\title{
Driving Factors of Preterm Birth Risk in Adolescents
} \author{
Molly J. Stout, $\mathrm{MD}, \mathrm{MSCl}^{1}$ \\ ${ }^{1}$ Department of Obstetrics and Gynecology, Washington University \\ School of Medicine, St. Louis, Missouri \\ ${ }^{2}$ Department of Epidemiology, College for Public Health and Social \\ Justice, Saint Louis University, St. Louis, Missouri \\ 3 Department of Obstetrics and Gynecology, Division of Maternal \\ Fetal Medicine, Atrium Health Women's Institute, Carolinas Medical \\ Center, Charlotte, North Carolina \\ ${ }^{4}$ Department of Obstetrics and Gynecology, Indiana University, \\ Indianapolis, Indiana
}

Marta J. Perez, $\mathrm{MD}^{1} \quad$ Jen J. Chang, $\mathrm{PhD}, \mathrm{MPH}^{2} \quad$ Lorene A. Temming, $\mathrm{MD}^{3} \quad$ Ebony B. Carter, MD, $\mathrm{MPH}^{1}$ Julia D. López, PhD, MPH, LCSW ${ }^{10}$ Methodius G. Tuuli, MD, MPH ${ }^{4}$ George A. Macones, MD, MSCE ${ }^{1}$

\begin{abstract}
Address for correspondence Molly J. Stout, MD, MSCI, Division of Maternal Fetal Medicine, Department of Obstetrics and Gynecology, Washington University School of Medicine, Campus Box 8064, 4566 Scott Avenue, St. Louis, MO 63110 (e-mail: mollystout@wustl.edu).
\end{abstract}

Am J Perinatol Rep 2020;10:e247-e252.

\begin{abstract}
Keywords

- spontaneous preterm birth

- indicated preterm birth

- adolescents

- risk factors

Objective We examined rates of spontaneous and indicated preterm births (S-PTB and I-PTB, respectively) and clinical risk factors for PTB in adolescents.

Study Design This is a population-based, retrospective cohort using 2012 U.S. natality data of nulliparous women who delivered a nonanomalous singleton birth between 20 and 42 weeks' gestation. Maternal age included $<16,16$ to 19.9 , and $\geq 20$ years. Rates of total, S-PTB, and I-PTB were compared across age groups. Multinomial logistic regression tested clinical risk factors for S-PTB.

Results In 1,342,776 pregnancies, adolescents were at higher risk for PTB than adults. The rate of total PTB was highest in young adolescents at $10.6 \%$, decreased to $8.3 \%$ in older adolescents, and $7.8 \%$ in adults. The proportion of S-PTB was highest in the youngest adolescents and decreased toward adulthood; the proportion of I-PTB remained stable across age groups. Risk factors for S-PTB in adolescents included Asian race, underweight body mass index (BMI), and poor gestational weight gain (GWG). In all age groups, carrying a male fetus showed a significant increased S-PTB, and Women, Infants, and Children's (WIC) participation was associated with a significantly decreased risk.

Conclusion The higher risk for PTB in adolescents is driven by an increased risk for SPTB. Low BMI and poor GWG may be potentially modifiable risk factors.

Condensation Adolescents have a higher risk for spontaneous PTB than adult women, and risk factors for spontaneous PTB may differ in adolescents.
\end{abstract}

Adolescents, ages 15 to 19 years, in the United States represented $2 \%$ of all births in $2015^{1}$ and multiple studies document an increased risk for unfavorable obstetric and neonatal outcomes' in this patient population including preterm delivery, low birth weight, eclampsia, and neonatal death. ${ }^{2-10}$

Many studies have demonstrated an increased risk for preterm delivery in adolescent patients though the precise reason for why adolescents may be at increased risk for preterm birth (PTB) is unknown. Some studies have suggested biologic immaturity of the gynecologic hormonal milieu may mediate the risk for preterm delivery. ${ }^{2-7,9,10}$ Multiple obstetrical events lead to PTB including spontaneous labor, premature rupture of membranes, and medical or obstetric complications leading to indicated (or provider received

September 27, 2019

accepted

April 6, 2020
DOI https://doi.org/

$10.1055 / \mathrm{s}-0040-1715164$. ISSN 2157-6998.
Copyright (c) 2020 by Thieme Medical Publishers, Inc., 333 Seventh Avenue, New York, NY 10001, USA. Tel: +1(212) 760-0888.
License terms

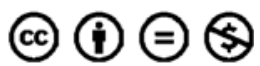


initiated) PTB. Adolescents are at increased risk for obstetric complications that may lead to either spontaneous or indicated РТВ. ${ }^{2-8,10,11}$ Understanding the primary reasons for PTB and, whether the etiology of PTB changes over the adolescent period, will allow for targeted, clinically relevant risk stratification and prevention strategies in this high-risk patient group. Thus, our aim was to examine the rates of PTB, and spontaneous and indicated PTB subtypes, across the adolescent period using United States natality data.

\section{Materials and Methods}

We conducted a population-based, retrospective cohort study using 2012 U.S. natality data including U.S. resident women who delivered a nonanomalous singleton first birth between 20 and 42 weeks of gestation. The natality file includes data on parental demographics, medical and obstetric characteristics, complications, and neonatal status at birth. Maternal age was categorized into young adolescent ( $<16$ years), older adolescent (16-19.9 years), and adult ( $\geq 20$ years) was used as the referent group. PTB was defined as delivery $<37$ weeks of gestation. PTB subtype was classified as spontaneous (S-PTB) or indicated (I-PTB) using available birth certificate data according to a previously documented and validated algorithm by Klebanoff et al. ${ }^{12,13}$ Briefly, S-PTB was defined as PTB after spontaneous labor or preterm rupture of membranes. I-PTB was defined as a preterm delivery for a maternal or fetal indication that required provider initiation of delivery.

Demographic characteristics available in natality data of young adolescent, older adolescent, and adults were compared with descriptive statistics. Race was self-reported. Body mass index (BMI), calculated as weight per height $\left(\mathrm{kg} / \mathrm{m}^{2}\right)$ and weight gain adequacy during pregnancy was categorized according to the 2009 Institute of Medicine guidelines. ${ }^{14}$ The Kotelchuck Index was used to assess adequacy of prenatal care defined as inadequate $(<50 \%$ of expected visits), adequate (80-109\% of expected visits), or adequate-plus ( $\geq 110 \%$ of expected visits). ${ }^{15}$

Total PTB rates, as well as proportions of S-PTB and I-PTB subtypes, were compared in young adolescents, older adolescents, and adults using Chi-square tests. Multinomial logistic regression models were used to estimate the relative risk ratio (RR) and its corresponding 95\% confidence intervals ( $95 \% \mathrm{CIs}$ ) for the association of the risk factors and type of PTB in each age group. All tests were two-tailed and $p<0.05$ considered significant.

All analyses were completed using STATA version 13.0 (StataCorp, College Station, TX). United States natality data are a publicly available dataset and qualified for exemption from Washington University Human Research Protection Office approval.

\section{Results}

A total of 1,342,776 deliveries met inclusion criteria of first nonanomalous singleton birth between 20 and 42 weeks of gestation. Demographic characteristics between young adolescents, older adolescents, and adults are shown in - Table 1.
Racial distribution varied across the age groups with a higher proportion of Black, American Indian, and Latin women in the adolescent age groups, whereas a higher proportion of Asian and White women were in the adult age group. The rate of underweight BMI was significantly higher in young adolescence and decreased in older adolescents and adults. Significantly fewer adolescents were overweight and obese. Genital infections of gonorrhea and chlamydia were more prevalent in adolescent groups compared with adult women. Reported tobacco use was highest in older adolescents compared with both younger adolescents and adult women.

Overall, adolescents have a higher risk for PTB than adult women (8.3 vs. $7.8 \% ; p<0.01)$ and the rate of total PTB was highest (10.6\%) in young adolescents and decreased to $8.3 \%$ in older adolescents and was lowest at $7.8 \%$ in adults (- Table $\mathbf{1}$ ). When examining the distribution of spontaneous and indicated PTB subtypes across age groups, the proportion of spontaneous PTBs was highest in the youngest adolescents and decreased toward adulthood ( - Table 2 ). The RR for spontaneous PTB was significantly higher in young adolescents ( $\mathrm{RR}=1.8,95 \% \mathrm{CI}: 1.7-1.9)$ compared with adults. The risk for older adolescents was still elevated compared with adults ( $R R=1.3,95 \% \mathrm{CI}: 1.2-1.3)$ though the magnitude of risk was less than that of the younger adolescent group. The proportion of indicated PTBs remained relatively stable at approximately $3 \%$ in all age groups.

Next, we explored whether common risk factors for spontaneous PTB change over maternal age groups ( - Table $\mathbf{3}$ ). Black race was significantly associated with S-PTB in the older adolescents and adults but not in the younger adolescent group. Asian race was a significant risk factor for S-PTB in adolescents of both $<16$ years and 16 to 19.9 years old. Underweight BMI was significantly associated with a risk for S-PTB in young adolescents and older adolescents but not in adults. Conversely overweight and obese BMI were not associated with S-PTB in younger women but were a significant risk factors in adults. Weight gain below the recommended guidelines was a significant risk factor for S-PTB in all age groups but was most strongly associated with S-PTB in adolescent mothers. Both inadequate and above adequate prenatal care were associated with S-PTB. Women, Infants, and Children's (WIC) assistance was associated with a significant decrease in S-PTB in all age groups, but most strongly in the youngest age group. Carrying a male fetus was associated with a significant increased risk for S-PTB across all age groups. Gonorrhea and chlamydial genital infections were not associated with S-PTB for any age group.

\section{Comment}

These data support the primary findings described further. First, adolescent mothers have an increased risk for PTB compared with nonadolescent adult mothers. Second, the risk for PTB is highest in the youngest group of adolescent mothers and decreases toward adulthood. The increased risk for PTB in adolescent mothers is predominantly due to an increased risk for the spontaneous PTB subtype. Lastly, the risk factors for spontaneous PTB in adolescent mothers do 
Table 1 Demographic characteristics of the sample from U.S. natality data

\begin{tabular}{|c|c|c|c|c|}
\hline & $\begin{array}{l}<16 \text {-year old } \\
(n=12,112)\end{array}$ & $\begin{array}{l}\text { 16-19.9-year old } \\
(n=206,701)\end{array}$ & $\begin{array}{l}\geq 20 \text {-year old } \\
(n=1,123,963)\end{array}$ & $p^{a}$ \\
\hline Maternal age (y) & $14.7 \pm 0.57$ & $18.0 \pm 1.0$ & $27.3 \pm 5.2$ & $<0.001$ \\
\hline \multicolumn{4}{|l|}{ Race } & \multirow[t]{6}{*}{$<0.001$} \\
\hline Black & $3,424(28.5)$ & $45,250(22.0)$ & $138,311(12.4)$ & \\
\hline American Indian & $198(1.7)$ & $3,063(1.5)$ & $6,838(0.6)$ & \\
\hline Asian & $119(1.0)$ & $2,699(1.3)$ & $97,815(8.6)$ & \\
\hline Latina & $5,069(42.2)$ & $69,406(33.8)$ & $200,272(17.9)$ & \\
\hline White & $3,217(26.7)$ & $85,019(41.4)$ & $672,988(60.4)$ & \\
\hline \multicolumn{4}{|l|}{ Body mass index } & \multirow[t]{8}{*}{$<0.001$} \\
\hline Underweight & $988(8.6)$ & $15,734(7.9)$ & $46,999(4.4)$ & \\
\hline Overweight & $2,228(19.3)$ & $43,014(21.6)$ & $255,900(23.7)$ & \\
\hline \multicolumn{4}{|l|}{ Obese } & \\
\hline Class I & $761(6.6)$ & $18,823(9.5)$ & $122,964(11.4)$ & \\
\hline Class II & $228(2.0)$ & $7,078(3.6)$ & $58,058(5.4)$ & \\
\hline Class III & $87(0.75)$ & 3,729 (1.9) & $40,417(3.8)$ & \\
\hline Normal weight & $7,232(62.8)$ & $110,598(55.6)$ & $554,732(51.4)$ & \\
\hline \multicolumn{4}{|l|}{ Gestational weight gain } & \multirow[t]{4}{*}{$<0.001$} \\
\hline Under & $3,191(28.1)$ & $44,699(22.8)$ & $187,220(17.6)$ & \\
\hline Over & $4,854(42.7)$ & $96,186(49.0)$ & $549,821(51.8)$ & \\
\hline Recommended & $3,311(29.2)$ & $55,306(28.2)$ & $325,481(30.6)$ & \\
\hline Tobacco use & 455 (3.9) & $21,641(11.1)$ & $74,560(7.0)$ & $<0.001$ \\
\hline Gonorrhea & $120(1.0)$ & $1,562(0.8)$ & $2,216(0.2)$ & $<0.001$ \\
\hline Chlamydia & $803(6.6)$ & $12,109(5.9)$ & $17,379(1.6)$ & $<0.001$ \\
\hline Preterm birth ( $<37$ weeks) & $1,288(10.6)$ & $17,151(8.2)$ & $87,205(7.8)$ & $<0.01$ \\
\hline
\end{tabular}

Note: data represented as mean \pm standard deviation or $n(\%)$.

${ }^{\mathrm{a} C h i}$-square test.

Table 2 Total preterm birth rates and spontaneous and indicated subtypes across maternal age categories

\begin{tabular}{|c|c|c|c|c|c|c|}
\hline Age (y) & PTB rate (\%) & $\begin{array}{l}\text { Spontaneous } \\
\text { PTB (\%) }\end{array}$ & $\begin{array}{l}\text { Indicated } \\
\text { PTB (\%) }\end{array}$ & $\begin{array}{l}\text { Proportion } \\
\text { spontaneous } \\
\text { (of all PTB) (\%) }\end{array}$ & $\begin{array}{l}\text { Relative risk for } \\
\text { spontaneous PTB }\end{array}$ & $p^{a}$ \\
\hline$<16(n=12,112)$ & 10.6 & 7.4 & 3.2 & 70 & $1.8(1.7-1.9)$ & $<0.01$ \\
\hline $16.0-19(n=206,701)$ & 8.3 & 5.3 & 3.0 & 64 & $1.3(1.2-1.3)$ & $<0.01$ \\
\hline$\geq 20(n=1,123,963)$ & 7.8 & 4.2 & 3.5 & 55 & REF & $<0.01$ \\
\hline
\end{tabular}

Abbreviation: PTB, preterm birth; REF, referent.

${ }^{\mathrm{a} C h i-s q u a r e ~ t e s t . ~}$

not reflect the same risk factors that are historically attributed to PTB, such as race and infection.

The findings in women of Black and Latin race, frequently considered to be at higher risk for PTB is noteworthy. The increased risk for spontaneous PTB in Black and Latin women in this data are seen only for older adolescents and more strongly for adult women but was not seen in the youngest group of women aged $<16$ years. However, in Asian mothers, the youngest age group had the highest risk for S-PTB with decreasing risk toward adulthood. These findings suggest that the risk relationship between race and spontaneous PTB may be more nuanced and may differ across age groups. Another main risk factor for S-PTB in adolescents appears to be underweight BMI and weight gain below the recommended guidelines. Although epidemiologic associations such as those detected in this analysis cannot comment on causality or interventions, these findings are hypothesis generating and suggest that adolescents may benefit from nutritional counseling and healthy weight gain goals during pregnancy.

Previous studies have attempted to determine the biological reasons for the observation of increased rates of PTB in adolescents. Gynecologic age (age at the time of conception 
Table 3 Association between clinical and demographic characteristics and risk for spontaneous preterm birth across maternal age groups

\begin{tabular}{|c|c|c|c|}
\hline Risk factor & $<16$-year old & 16-19.9-year old & $\geq 20$-year old \\
\hline \multicolumn{4}{|l|}{ Race } \\
\hline Black & $1.10(0.88-1.37)$ & $1.23(1.16-1.31)$ & $1.42(1.38-1.47)$ \\
\hline American Indian & $0.68(0.31-1.51)$ & $1.11(0.92-1.34)$ & $1.30(1.15-1.47)$ \\
\hline Asian & $2.10(1.15-3.85)$ & $1.45(1.23-1.72)$ & $1.04(1.00-1.08)$ \\
\hline Latina & $0.98(0.80-1.20)$ & $1.07(1.01-1.13)$ & $1.13(1.10-1.17)$ \\
\hline White & REF & REF & REF \\
\hline \multicolumn{4}{|l|}{$\mathrm{BMI}$} \\
\hline Underweight BMI & $1.49(1.73-1.90)$ & $1.30(1.21-1.39)$ & $1.06(1.00-1.11)$ \\
\hline Overweight & $0.96(0.76-1.20)$ & $1.08(1.02-1.15)$ & $1.24(1.20-1.27)$ \\
\hline Obese & $0.80(0.58-1.11)$ & $0.94(0.87-1.00)$ & $1.14(1.11-1.18)$ \\
\hline Normal weight & REF & REF & REF \\
\hline \multicolumn{4}{|c|}{ Recommended weight gain based on BMI } \\
\hline Under recommended & $2.51(2.01-3.02)$ & $1.98(1.88-2.09)$ & $1.80(1.76-1.85)$ \\
\hline Over recommended & $0.55(0.43-0.69)$ & $0.26(0.53-0.59)$ & $0.59(0.57-0.60)$ \\
\hline At recommended & REF & REF & REF \\
\hline \multicolumn{4}{|c|}{ Kotelchuck's prenatal index } \\
\hline Inadequate & $2.06(1.62-2.63)$ & $2.11(1.97-2.26)$ & $2.14(2.07-2.22)$ \\
\hline Adequate + & $3.74(2.90-4.81)$ & $4.92(4.61-5.24)$ & $5.59(5.43-5.75)$ \\
\hline Adequate & REF & REF & REF \\
\hline \multicolumn{4}{|l|}{ Infant sex } \\
\hline Male & $1.27(1.08-1.48)$ & $1.20(1.15-1.26)$ & $1.25(1.22-1.28)$ \\
\hline Female & REF & REF & REF \\
\hline Tobacco use & $1.06(0.70-1.61)$ & $1.25(1.17-1.34)$ & $1.39(1.34-1.45)$ \\
\hline WIC assistance & $0.55(0.46-0.66)$ & $0.71(0.67-0.75)$ & $0.86(0.84-0.89)$ \\
\hline Gonorrhea & $1.71(0.84-3.46)$ & $1.23(0.98-1.55)$ & $1.13(0.92-1.38)$ \\
\hline Chlamydia & $0.77(0.54-1.09)$ & $0.98(0.89-1.08)$ & $1.08(1.00-1.17)$ \\
\hline
\end{tabular}

Abbreviations: BMI, body mass index; REF, referent; WIC, Women, Infants, and Children.

Note: data shown as relative risk with $95 \%$ confidence intervals.

of incident pregnancy - age at menarche) has been used as a measurement of physiologic maturity in adolescent pregnancies. In 1997, Hediger et al reported a prospective cohort of pregnant patients enrolled from 1985 to 1995 and reported a 75\% increased risk for PTB in adolescent patients, which is similar to the magnitude seen in our data. ${ }^{5}$ Also similar to our data, they found that low maternal weight was a risk factor for PTB. However, they also report that low gynecologic age was associated with a more than two-fold increased risk for PTB, leading the authors to conclude that biologic immaturity, as opposed to social conditions, mediates the increased risk for preterm delivery seen in adolescents. Kaplanoglu et al reported on a cohort of pregnant women from Turkey and found that gynecologic age $<3$ years was associated with a significantly increased risk for multiple adverse obstetric outcomes. ${ }^{6}$ Although we cannot calculate gynecologic age from birth certificate data, our findings in a modern U.S. cohort suggest that the pathophysiology of PTB may be different in adolescent mothers than adults. It is unknown whether the racial risk factors and low maternal weight/poor weight gain risk factors found in our study, as well as described by Hediger et al, ${ }^{5}$ are related to or separate from the risk factor of gynecologic immaturity.

Carrying a male fetus compared with a female fetus was associated with increased risk for spontaneous PTB. This finding did not seem to be uniquely associated with young maternal age as the same magnitude of risk was seen across all age groups (20-27\%). The increased risk associated with carrying a male fetus has been previously reported ${ }^{16-18}$ and may be a risk factor for nonresponsiveness to PTB prevention with 17-hydroxyprogesterone caproate. ${ }^{19}$

\section{Strengths and Limitations}

The strengths of this study include a large sample size and diverse population of births taken from U.S. natality data reflective of a modern U.S. cohort. Additionally, our study examines not only the risk for preterm delivery but also 
whether the birth occurred to due spontaneous preterm delivery or indicated preterm delivery. Identification of risk factors in a modern U.S. cohort of adolescents can form the basis for evidence-based clinical interventions to test in this high-risk population to help decrease adverse obstetric outcomes and improve both maternal and neonatal health. We used a previously described algorithm that has undergone validation by comparison of birth certificate categorization to medical chart data. ${ }^{12,13}$

Limitations of our findings should be considered. First, this study is a retrospective one, based on data reported in natality records, and is subject to errors inherent to vital statistics such as errors in self-reporting and misclassification. There are limitations to the use of natality data including the inability to assess all demographic and behavior risks for PTB if they aren't captured in natality data such as substance use, education, or occupation. There was minimal missing data for most variables used in this analysis $(<1 \%)$ with the exception of $4.9 \%$ missing data for prenatal care which is most likely missing at random and should not have significant impact on the generalizability of our study findings. Nonetheless, using natality data allowed analysis of a modern U.S. population is large enough to detect trends in smaller subgroups of the population. Second, there is the possibility for misclassification of type of PTB. Based on the algorithms by Klebanoff et al and Stout et al for classification of PTBs as spontaneous or indicated by birth certificate data, ${ }^{12,13}$ there is a risk for over-classification of births as spontaneous and under-classification as indicated. Based on the algorithm by Klebanoff et al assessment of S-PTB was correct $85 \%$ of the time. This error, inherent to how data are reported on birth certificates, could have inflated our risks for the spontaneous PTB subtype. However, in a sensitivity analysis performed in our data, if $15 \%$ of S-PTBs were reclassified as I-PTB, the rates of S-PTB in adolescents are still higher (6.3\% S-PTB vs. $4.3 \%$ I-PTB in adolescents $<16$ years; and $4.5 \%$ S-PTB vs. $3.7 \%$ I-PTB in those aged $16-19$ years). Lastly, there is no way to calculate gynecologic age from birth certificate data preventing us from stratifying adolescents into younger and older based on gynecologic age instead of chronologic age.

\section{Conclusion}

Our data strengthen existing literature highlighting the increased risk of PTB among adolescents in a modern, diverse U.S. cohort. Adolescents aged $<16$ years are at particular risk for PTB and often may be nulliparous without obstetric history to guide prophylaxis strategies. Thus, it is important to understand what clinical characteristics and physiology drive this risk to guide evidence-based risk assessment and possible prevention strategies. It cannot be assumed that interventions for achieving adequate weight before pregnancy, or appropriate weight gain during pregnancy will mitigate the risk for PTB. However, these findings suggest that such interventions should be studied as they may represent potentially modifiable risk factors for this atrisk adolescent population.

\section{Poster Presentation Information}

This data was presented at the 37th Annual Society for Maternal Fetal Medicine Meeting, January 2017, Las Vegas, Nevada.

\section{Funding}

M.J.S. has support from NIH/NICHD Women's Reproductive Health Research Career Development Program at Washington University in St. Louis (5K12HD063086-05), and The March of Dimes Prematurity Research Center at Washington University in Saint Louis. E.B.C. has support from the Robert Wood Johnson Foundation (74250). M.G. T. had support from NIH/NICHD Women's Reproductive Health Research Career Development Program at Washington University in St. Louis (5K12HD063086-05). The above funding sources had no role in the study design, collection/analysis/interpretation of data, or manuscript preparation. The contents of this publication are solely the responsibility of the authors and do not necessarily represent the official view of the foundation or federal support entities.

\section{Conflict of Interest}

None declared.

\section{References}

1 Martin JA, Hamilton BE, Osterman MJ. Births in the United States, 2015. NCHS Data Brief 2016;(258):1-8

2 Althabe F, Moore JL, Gibbons L, et al. Adverse maternal and perinatal outcomes in adolescent pregnancies: the Global Network's Maternal Newborn Health Registry study. Reprod Health 2015;12(Suppl 2):S8

3 Fraser AM, Brockert JE, Ward RH. Association of young maternal age with adverse reproductive outcomes. N Engl J Med 1995;332 (17):1113-1117

4 Ganchimeg T, Ota E, Morisaki N, et al; WHO Multicountry Survey on Maternal Newborn Health Research Network. Pregnancy and childbirth outcomes among adolescent mothers: a World Health Organization multicountry study. BJOG 2014;121(Suppl 1):40-48

5 Hediger ML, Scholl TO, Schall JI, Krueger PM. Young maternal age and preterm labor. Ann Epidemiol 1997;7(06):400-406

6 Kaplanoglu M, Bülbül M, Konca C, Kaplanoglu D, Tabak MS, Ata B. Gynecologic age is an important risk factor for obstetric and perinatal outcomes in adolescent pregnancies. Women Birth 2015;28(04):e119-e123

7 Kawakita T, Wilson K, Grantz KL, Landy HJ, Huang CC, GomezLobo V. Adverse maternal and neonatal outcomes in adolescent pregnancy. J Pediatr Adolesc Gynecol 2016;29(02):130-136

8 Kirbas A, Gulerman HC, Daglar K. Pregnancy in adolescence: is it an obstetrical risk? J Pediatr Adolesc Gynecol 2016;29(04):367-371

9 Stevens-Simon C, Barrett J, McGregor JA, French J, Persutte W. Short cervix: a cause of preterm delivery in young adolescents? J Matern Fetal Med 2000;9(06):342-347

10 Torvie AJ, Callegari LS, Schiff MA, Debiec KE. Labor and delivery outcomes among young adolescents. Am J Obstet Gynecol 2015; 213(01):95.e1-95.e8

11 Harper LM, Chang JJ, Macones GA. Adolescent pregnancy and gestational weight gain: do the Institute of Medicine recommendations apply? Am J Obstet Gynecol 2011;205(02):140.e1-140.e8

12 Klebanoff MA, Yossef-Salameh L, Latimer C, et al. Development and validation of an algorithm to determine spontaneous versus provider-initiated preterm birth in US vital records. Paediatr Perinat Epidemiol 2016;30(02):134-140 
13 Stout MJ, Macones GA, Tuuli MG. Accuracy of birth certificate data for classifying preterm birth. Paediatr Perinat Epidemiol 2017;31 (03):245-249

14 Institute of Medicine (US) and National Research Council (US) Committee to Reexamine IOM Pregnancy Weight Guidelines; Rasmussen KM, Yaktine AL, eds. Weight Gain During Pregnancy: Reexamining the Guidelines. Available at: https://www. cbsnews.com/htdocs/pdf/052809_pregnancy.pdf. Accessed April 22, 2020

15 Kotelchuck M. The adequacy of prenatal care utilization index: its US distribution and association with low birthweight. Am J Public Health 1994;84(09):1486-1489
16 Brettell R, Yeh PS, Impey LW. Examination of the association between male gender and preterm delivery. Eur J Obstet Gynecol Reprod Biol 2008;141(02):123-126

17 Challis J, Newnham J, Petraglia F, Yeganegi M, Bocking A. Fetal sex and preterm birth. Placenta 2013;34(02):95-99

18 Zeitlin J, Saurel-Cubizolles MJ, De Mouzon J, et al. Fetal sex and preterm birth: are males at greater risk? Hum Reprod 2002;17(10):2762-2768

19 Manuck TA, Stoddard GJ, Fry RC, Esplin MS, Varner MW. Nonresponse to 17-alpha hydroxyprogesterone caproate for recurrent spontaneous preterm birth prevention: clinical prediction and generation of a risk scoring system. Am J Obstet Gynecol 2016;215 (05):622.e1-622.e8 